\title{
SOBRE EL INSTINTO. \\ EL PARADIGMA FIXISTA DEL INSTINTO FRENTE A LA REVOLUCIÓN DARWINIANA
}

Jorge Martínez Contreras

\begin{abstract}
Universidad AUtónoma Metropolitana
Si no existieran los animales, la naturaleza del hombre nos sería aún más incomprensible.
\end{abstract}

BUFFON

En las ciencias del comportamiento animal -en la etología y en la psicología experimental comparada, fundamentalmente- hay dos polos complementarios de referencia entre los que se desarrolla su estudio y su discurso sobre los resultados de sus investigaciones: inteligencia e instinto. El primero conlleva otro, implícito, de cuya presencia en el mundo animal, a partir de cierto grado de complejidad conductual (vertebrados para unos, mamíferos exclusivamente para otros), dudan pocos científicos: el pensamiento.

Como parte de una investigación más amplia sobre el desarrollo teórico y empírico de la etología, me propongo discutir aquí cómo se orientaba el estudio del segundo de los conceptos, el instinto, en el primer tercio del siglo xIx, y cómo la revolución darwiniana creó nuevas bases conceptuales en relación con el origen de este fenómeno.

La revolución darwiniana ha sido estudiada por varios naturalistas y filósofos, por lo que no es necesario, en mi opinión, más que recordar algunos aspectos de la misma, con los que concuerdan la mayoría de los darwinistas modernos (aunque no sea el caso, por supuesto, de importantes escuelas no darwinistas, como la que Grassé encabeza en Francia).

Una de las mejores síntesis de lo anterior nos la da E. Mayr (1971) en "The Nature of Darwinian Revolution": ${ }^{1}$ empieza quejándose de que Kuhn y sus seguidores, al trabajar sobre problemas donde sobresalen los nombres de Copérnico, Newton, Lavoisier, Darwin, Planck, Einstein y Heisenberg, hayan favorecido el concepto limitado de revolución científica en las ciencias físicas (léase naturales) exclusivamente. Para Mayr, la revolución darwiniana va mucho más lejos, pues abarca no sólo el campo de las ciencias físicas sino todo el universo intelectuali, por lo que amerita un estudio y un desarrollo especiales:

1 Revised from "The Nature of the Darwinian Revolution", Science, 176 (1971) en Evolution and Diversity of Life, Harvard U. Press, 1976, pp. 277-296. 
I am taking a new look at the Darwinian revolution of 1859, perhaps the most fundamental of all intellectual revolutions in the history of mankind. It not only eliminated man's anthropocentrism, but affected every metaphysical and ethical concept, if consistently applied. ${ }^{2}$

Estamos de acuerdo en lo fundamental de esta frase. Darwin realizó, en efecto, una genuina revolución científica: la revolución darwiniana desplazó un paradigma que imperaba sobre la ciencia (en su manifestación sociológica y, parcialmente, en la científica), sin por ello poder confirmar todas las intuiciones fundamentales del paradigma o los paradigmas transformacionistas opuestos. En efecto, el viejo y duradero paradigma creacionista, y su expresión científica en la sistemática fixista, así como sus corolarios, las múltiples creaciones, el catastrofismo, fueron desplazados del mundo científico dominante, aunque debieron librarse -y se libran todavía - batallas de retaguardia.

Las teorias fixistas se imponían no sólo porque gran parte de sus defensores ocupaban importantes puestos en los aparatos político-cientificos de la época —Cuvier, Owen, Agassiz, etc.-, sino que también parecian tener en su favor tanto mejores argumentos conceptuales como un enorme cúmulo de datos científicos. La mejor imagen de esta situación la tenemos en el análisis de los famosos debates en el seno de la Academia de Ciencias francesa entre Georges Cuvier y Étienne Geoffroy St.-Hilaire, discusiones en las que Goethe tomó partido, como espectador involucrado y como cronista. ${ }^{3}$ Todos concuerdan en afirmar que el debate fue una victoria política de Geoffroy, pero, al mismo tiempo, una derrota científica del padre de la teratología frente al "Napoleón de las ciencias", pues no logró presentar ninguna prueba empirica que constituyera un verdadero contraejemplo paradigmático (el debate, que tuvo lugar en 1830, girb alrededor de la paleontología comparada y de la sistemática).

Cierto es que, en 1859, Darwin sacó beneficio del desarrollo de disciplinas como la geología (Lyell), la paleontología (G. Cuvier), la paleontología comparada (E. Geoffroy), la estratigrafía, la biogeografía, el estudio de los animales domésticos (F. Cuvier, Isidore Geoffroy, Roulin), etc., que aportaban una masa en continuo crecimiento de elementos en favor del paradigma contrario, a saber: el transformacionismo, sin des-

2 Ibid., p. 277.

3 Ver en especial: Piveteau, J., "Le Débat entre Cuvier et Geoffroy St.-Hilaire", Rev. d'hist. des Sci., 3 (1950), pp. 343-363; Geoffroy St.-Hilaire, E., Principes de philosophie zoologique discutés en mars 1830 au sein de l'Académie Royale des Sciences, Paris, Pichon et Didier, 1830, 226 pp.; Goethe, J. W. von, Principes de philosophie zoologique, S. F. N. L. (1830), 15 pp. 
cartar las geniales intuiciones en ese sentido expresadas desde hacía más de un siglo: Maupertuis, De Maillet, Buffon, Erasmo Darwin, pero, en particular, Lamarck y la visión modificada del transformacionismo de E. Geoffroy. Pues es cierto que el darwinismo coincide con el transformacionismo en que hay evolución, cambio irreversible de estructuras morfológicas y conductuales en el transcurrir de las generaciones, y se opone de la misma manera radical al creacionismo y su mundo (o mundos, si hubo varias creaciones) estático, al defender la idea de un mundo dinámico.

Sin embargo, la revolución darwiniana no aparece como la confirmación de las intuiciones que anunciaba el paradigma transformacionista, y todavia menos de las de Lamarck (herencia de caracteres adquiridos) o de E. Geoffroy (la evolución tiene lugar en el periodo embrionario). Por el contrario, el darwinismo difiere de ese paradigma en un aspecto fundamental: en la idea de que existe un mecanismo llamado selección natural, que actúa favorable o desfavorablemente sobre caracteres que aparecen al azar, contribuyendo así al crecimiento o desaparición de las especies; todos sabemos lo que esta teoría le debe al sociólogo y demógrafo de finales del siglo xvir: Malthus.

A pesar de su aparente proximidad conceptual al transformacionismo, el darwinismo reúne aún más claramente las características de una revolución "à la Kuhn" si, como trataré de mostrarlo en el caso del instinto, se ve lo mucho que debe al paradigma fixista: al tratar de resolver algunas paradojas de este sistema, acaba destruyendo el núcleo central del mismo y abriendo una nueva visión de la biología, sin por ello convertir en ganadores a los lamarckianos.

El darwinismo de hoy se confunde con el neodarwinismo que es, en mi opinión, el verdadero paradigma dominante actual en las ciencias de la vida, a pesar de los constantes anuncios en el sentido contrario. ${ }^{4}$ El neodarwinismo consiste fundamentalmente en haber podido introducir de manera enriquecedora, y sin destruir el núcleo de la teoría darwiniana, la genética mendeliana (y después a Morgan y sucesores) que Darwin no conoció y que está en oposición con el lamarckismo, y que parece incluso favorecer algunas tesis de corte fixista, como las de Frédéric Cuvier, que analizaremos más tarde: la no herencia de los caracteres adquiridos, que Weismann expresó en 1883. Posteriormente, la nueva síntesis neodarwiniana incluirá, además de la genética, la dinámica y sistemática de las poblaciones, cuyo padre moderno es el propio E. Mayr, y la paleontologia de George C. Simpson. ${ }^{5}$

4 Cfr. Blanc, Marcel, "Les Théories de l'évolution aujourd'hui" en La Recherche, I29, enero 1982, pp. 26-40.

5 Ibid. 
Si la teoría propiamente darwiniana ha podido permanecer en el ca razón de estas nuevas síntesis, a pesar de haber tenido bases genéticas tan débiles y hasta contradictorias, es prueba de que se trató de un paradigma epistemológico muy fructífero, que se refleja en otro aspecto de la revolución darwiniana: el naturalista inglés propone un mecanismo preciso de selección natural. Los individuos que, por azar, nacen más aptos, tienen, en consecuencia, más descendencia. Esta teoría es la denominada alopátrica: ella establece que "las poblaciones deben estar separadas por accidentes geográficos antes de divergir gradualmente en sus caracteres y producir nuevas especies". ${ }^{6}$ Aquí el azar juega el papel fundamental, y por ello se encuentra actualmente en acalorada discusión $\mathrm{y}$, tal vez, en pérdida de argumentos y pruebas frente a las teorías simpátricas, que suponen "que los individuos adaptados a un nicho particular en el seno de un área de dispersión, permanecen ligadós activamente a ese nicho y no se cruzan más que entre sí, rechazando compañeros sexuales de su misma especie y área". ${ }^{7}$ En esta teoría el azar juega un papel menor; de ahí las afirmaciones en el sentido de un posible "esfuerzo" de los animales por permanecer en su nicho, lo que implicaría un resurgimiento del lamarckismo. Aunque este problema no es tema del presente trabajo, he querido recordarlo para destacar la importancia de la biogeografía en la revolución darwiniana y su concomitante ausencia en quien no pudo ni siquiera concebirla: F. Cuvier.

Volviendo a la frase de Mayr (Cfr., p. 00), para mí la riqueza de la teoría darwiniana se extiende sin duda a muchos campos intelectuales, aunque tengo fuertes dudas de que su aplicación sea heurística en el contexto de los fenómenos culturales. Sin embargo, creo que sí se aplica a los fenómenos etológicos con la misma eficacia que a otro tipo de fenómenos biológicos, lo que automáticamente implica que aquellos fenómenos son todos, inclusive los humanos, reducibles a los biológicos. ${ }^{8}$

En los límites de la presente comunicación, pretendo discutir las tesis de uno de los padres de la psicología experimental animal, y ver cómo sus tesis fixistas constituyeron un paradigma de cuya ruptura surgió el paradigma etológico darwiniano, el cual, sin embargo, no destruyó totalmente lo fundamental de las intuiciones cuvieranas.

La diferencia entre los que crearon paradigmas centrales y los que sólo aportaron a la ciencia brillantes intuiciones o interesantes obser-

6 Ibid., p. 32. Traducida por mi, asi como todas las demás citas originalmente en francés.

7 Ibid.

8 La etología humana ha tenido un desarrollo asombroso en los últimos años gracias, en particular, a los trabajos de un discipulo de Lorenz, Eibl-Eibesfeld. Pero los orígenes de esta disciplina están en La Expresión de las emociones en el hombre $y$ en los animales, publicado por Darwin en 1872. 
vaciones y experiencias, depende, en nuestra opinión, de la posesión simultánea de dos elementos: 1) la teoría o teorías que den cuenta de manera convincente ante la comunidad científica, o una fracción significativa de la misma, de 2) los también nuevos aportes empíricos. De la unión de ambos nacerá la nueva teoría, que traerá consigo la reinterpretación de antiguos datos empíricos y la generación de otras vetas de la investigación. ${ }^{9}$

\section{Frédéric Cuvier}

Darwin conoció los trabajos de F. Cuvier. Es casi seguro que leyó su artículo "Instinto" en el Dictionnaire d'histoire naturelle, ${ }^{10}$ obra de consulta casi obligada para los naturalistas de la época. En todo caso, sí conoció el artículo "Examen de quelques observations de M. DugaldSteward, qui tendent à détruire l'analogie des phénomènes de l'Instinct avec ceux de l'habitude", 11 que menciona:

Frédéric Cuvier and several of the older metaphysicians have compared instinct with habit. ${ }^{12}$

Hay que destacar aquí la expresión "viejos metafísicos", dirigida al creacionismo más implícito que explícito en la obra del hermano menor de Georges Cuvier. En efecto, F. Cuvier, a pcsar de contar coñ una gran masa de datos empíricos, producto de sus propias investigaciones, no podía acercarse a las tesis darwinianas por dos razones fundamentales: la teoría creacionista jugaba el papel de un paradigma científico reaccionario (por oposición a "revolucionario") y no contaba con la experiencia de campo de un Darwin, en particular la esencial experiencia de las Islas Galápagos, donde lo fundamental de las tesis alopátricas de Darwin tendrá su origen.

Tomaré como modelo paradigmático del "fixismo etológico" los trabajos del autor francés y los compararé con los del capítulo VIII, "Instinct", del Origen de las Especies, pues este último fragmento constituye

9 Aunque una teoría errónea, como es, en mi opinión, la Sociobiología, puede generar una veta de nuevos datos empíricos o una interesante reinterpretación de los ya existentes.

10 Strasbourg, Levrault, 1824.

11 Mémoires du Muséum d'histoire Naturelle, vol. 10, 1823, pp. 116-128. La mención que hace Darwin se encuentra al inicio del cap. VIII: "Instinct" en The Origin of Species by Means of Natural Selection, en "The Great Books of the Western World", Encyclopaedia Britannica, Inc., 1952, Vol. 23, p. 119.

12 Ibid. 
para nosotros el origen teórico de la etología (aunque no el origen del término)..$^{13}$

La idea de que los animales son presa fácil de sus "pasiones" y actúan de acuerdo con una relación de simpatía connatural con la naturaleza, existe desde Heródoto y la expresa a menudo el Estagirita. Fue Cicerón quien creó el término de instinto como impulso., ${ }^{14}$

Dentro de una teoría fixista de los fenómenos de la vida, el instinto debe ser concebido como un impulso fijo y constante, en una especie dada, a realizar determinadas acciones, todas ligadas más a la supervivencia de la especie que a la supervivencia del individuo que las ejecuta. Georges Cuvier aportó la definición fixista que constituye el paradigma teórico del término en el mundo científico del primer tercio del siglo $\mathrm{xIx}$ :

Existe, en un gran número de animales, una facultad diferente de la inteligencia; es aquella llamada instinto. Esta les hace producir ciertas acciones activas necesarias a la conservación de la especie, pero a menudo totalmente extrañas a la necesidad aparente de los individuos, a veces también muy complicadas y que, si debieran ser atribuidas a la inteligencia, supondrían una previsión y conocimientos infinitamente superiores a aquellos que se pueden admitir en las especies que las ejecutan. Las acciones producto del instinto no son tampoco el efecto de la imitación, pues los individuos que las practican generalmente no las han visto hacer nunca a otros; nunca están en proporción con la inteligencia ordinaria, por el contrario, se vuelven más singulares, más sabias, a medida que los animales pertenecen a clases más elevadas, aunque más estúpidas en todo lo demás. Son tan claramente propiedad de la especie, que todos los individuos las ejecutan de la misma manera sin perfeccionarlas en nada. ${ }^{15}$

G. Cuvier la ilustrará con el viejo ejemplo de las abejas, utilizado desde Aristóteles, ${ }^{16}$ para mostrar el aparente ingenio de animales a los que nadie ha podido atribuir seriamente algo de razón:

13 Isidore Geoffroy St.-Hilaire lo acuñó en 1854. Ver a ese respecto mi trabajo: "¿̨Se puede hacer una descripción neutra del comportamiento animal? Los intentos opuestos de dos precursores de la etología: E. Geoffroy y F. Cuvier", presentado en el IV Simposio Internacional de Filosofía, IIF, UNAM.

14 Actualmente el concepto de instinto es demasiado amplio como para seguir siendo usado de la misma manera; se ha descompuesto en varios otros: celo, territorialidad, "imprinting", etc. No así el de inteligencia.

15 Citado por P. Flourens, Psychologie Comparée, 2a edición, París, Garnier Frères, 1864, III, pp. 18-19.

16 Aunque Charles Singer supone que el estudio sobre las abejas, por malo, no es del mismo Aristóteles, sino de un apicultor de la época (A History of Biology, N. Y., Abelard-Schuman, 1962, pp. 35-37). 
Las abejas construyen desde el comienzo del mundo edificios muy ingeniosos, calculados siguiendo la más alta geometría y destinados a alojar y a alimentar a una posteridad que no es ni siquiera su propia descendencia. Las abejas y las avispas solitarias forman de esta manera nidos muy complicados para depositar en ellos sus huevos. Sale de este huevo un gusano (ver), que nunca ha visto a su madre, que no conoce nada de la estructura de la prisión donde está encerrado y que, una vez metamorfoseado, construye sin embargo una perfectamente semejante para su propio huevo. ${ }^{17}$

He subrayado "desde el comienzo del mundo" para mostrar que Georges no se permite ni siquiera una hipótesis que no sea creacionista. Frédéric, protestante creyente y creacionista como aquél, tendrá sin embargo una experiencia en el estudio de animales vivos en cautiverio -en particular mamíferos de todo tipo-, gracias a su gestión a la cabeza de la Ménagerie del Museo de Historia Natural, que supera a la de cualquier europeo contemporáneo. Lo que notará rápidamente nuestro naturalista es que los animales a su cargo no son, en sus instintos, "tan precisos" como los insectos: hay variaciones en las especies, razas e individuos, debidas a la manera como se presenta el celo, a la alimentación, al clima, al contacto con los cuidadores, a hechos fortuitos y a individualidades, todo lo cual le impide afirmar un total fixismo, con el propósito paradójico de salvar el fixismo como teoría central de la biología. En efecto, Frédéric fue un gran conocedor de animales y de especies salvajes, domesticadas (domesticidad aprendida: leones, focas, simios, etc.) y domésticas (domesticidad heredada: perros, etc.) y trató de dar cuenta, a la manera fixista, de observaciones que aparentemente favorecían las tesis transformacionistas. Por ello se situará no sólo más cerca de Darwin que su propio colega - y sucesor de G. Cuvier en la Academia- Flourens, sino también más que Romanes, el discípulo de Darwin que tanto hizo por describir el instinto. ${ }^{18}$ Aquél utilizará el concepto de inteligencia animal, calificándola de inferior, oscura, etc., para explicar paradojas aparentes del mundo animal, como la "corrección" por los animales de obras destruidas parcialmente. ¿Cómo puede una oruga saber dónde recomenzar su capullo, si el instinto es ciego? ¡Pues sí lo sabe! Para Flourens hay un nivel elemental de inteligencia, que respecto al hombre posee simplemente una diferencia de grado. Nos da como ejemplo la observación de Roesel (Reimarus), quien destruía una parte de la obra de una oruga y observaba que "ésta se paraba un momento, como si la violencia le hubiera hecho nacer las

17 Citado por P. Flourens, op. cit.

18 Romanes, George John, L'Evolution mentale chez les animaux, París, C. Reinwald, 1884, 412 pp. 
ganas de suspender totalmente su trabajo; sin embargo, algunos instantes después se ponía a reacomodar lo que había sido desgarrado y continuaba la terminación de su capullo". ${ }^{19}$ (Darwin citará un ejemplo semejante de una observación más precisa llevada a cabo por Huber.) ${ }^{20}$

En lo que respecta a Romanes, éste, de igual manera por cierto que Flourens, hablará de instintos perfectos e imperfectos, como Aristóteles escribía sobre huevos perfectos (aves y algunos reptiles) e imperfectos (insectos, etc.). En ninguno de los dos casos se ha visto la especificidad orgánica del instinto tan claramente como la percibió Frédéric.

En las ciencias biológicas no se puede defender o atacar con éxito un paradigma si no se cuenta con datos empíricos interesantes de primera mano. F. Cuvier, como Darwin, los tenía.

Por razones de espacio, no citaré más que los rasgos sobresalientes del trabajo del francés, lo que permitirá al lector ver que varios de los "descubrimientos" recientes de los etólogos, son redescubrimientos de estudios no sólo del siglo xrx, sino inclusive de observaciones del mismo Aristóteles.

\section{La sociabilidad animal y humana}

A finales del siglo xvin y principios del $\mathrm{xIx}$, las tesis rousseaunianas estaban de moda: la existencia de una especie de paraíso perdido en que los hombres habían vivido, solitarios, una vida en concordancia con la naturaleza y donde sólo las fuerzas del amor creaban una sociedad momentánea, era una idea compartida; la civilización había sido un accidente, y la injusticia entre los hombres, una aberración que únicamente un contrato social (una convención) podría corregir. F. Cuvier afirmará, en contra de esas tesis, que si el hombre es sociable, lo es por naturaleza, impulsado por una fuerza innata llamada instinto, y no por accidente o convención.

La sociabilidad del hombre es el efecto de una tendencia, de una necesidad natural, que lo lleva incontrolablemente a acercarse a sus semejantes, independientemente de toda modificación anterior, de toda reflexión, de todo conocimiento. Es una especie de instinto que lo domina y que los pueblos más salvajes manifiestan con tanta fuerza como las naciones más civilizadas. ${ }^{21}$

$\mathrm{Y}$ añadirá lo que es sin duda cierto, a saber, que "la idea de que el

19 Flourens, op. cit., p. 9 ss.

20 The Origin of Species, op. cit., p. 120.

21 "De la sociabilité des animaux", Mémoires du Muséum d'histoire naturelle, T. XIII, 1925, p. 3. 
hombre de naturaleza vive en soledad no ha sido nunca resultado de la observación".22

Partiendo de la realidad del instinto, Cuvier sentará las bases de posteriores estudios, como los de Lorenz: la sociabilidad innata puede ser constante, como en el perro, cuya relación amable con el hombre -o con un león - no se modificará por causa de los hábitos. Un perro criado con lobos salvajes manifiesta una sociabilidad idéntica hacia el hombre cuando es separado de aquéllos. Por el contrario, el instinto gregario puede desaparecer: los ciervos jóvenes que viven en grupo con hembras en una época de su vida, pierden hábitos e instinto simultáneamente cuando son adultos y, se haga lo que se haga, en lo sucesivo llevan, salvo en época de celo, una existencia solitaria.

Cuvier tiene una visión mecanicista de los animales: éstos sólo son guiados por pasiones (palabra que agradaría a Aristóteles) e impulsos incontrolables. El celo, la necesidad de dominar y ser "jefe", o, por el contrario, de obedecer ciegamente cuando se es dominado, son fenómenos que Cuvier ilustra con diferentes observaciones, en muchas de las cuales tuvo el acierto de hacer experiencias interespecíficas; por ejemplo: un león y un perro son criados juntos; el perro llega a la edad adulta antes que el león y ejerce, como en su mundo perruno, su dominación; el felino se acostumbra a ella y la acepta, aunque sea cuatro veces más grande y mucho más fuerte que el can; sin embargo, si el perro muere, el león adopta otro can rápidamente, aunque ya no admita su situación de dominado; en el caso contrario, el perro puede morir de tristeza ante la desaparición del león. Al comprobar estos fenómenos, que se repiten de manera casi idéntica en varios casos y en varios paises, Cuvier puede afirmar que se trata de instintos y no de hábitos.

También se documentó Cuvier sobre varios casos de "jefaturas" animales: entre conejos, un viejo fue reconocido como líder por decenas y decenas de descendientes: al sonido de un silbato que los llamaba a la conejera nocturna, arribaba siempre primero el viejo, pero dejaba entrar a todos para ingresar él al final. Un bravo chivo de Cachemira, que mide la mitad que los compañeros europeos de su encierro y que, a pesar de haber perdido un cuerno, los domina y está siempre dispuesto a enfrentarse con todo rival potencial. $O$ aquel bisonte americano, que aprende a reconocer a su cuidador, a quien teme y frente a quien se subordina, por la forma de su vestimenta; el bisonte lo obedece en todo momento y tiembla cuando aquél le ordena algo, pero un día el cuidador entra con otra indumentaria y sólo su agilidad lo salva de ser muerto por el enfurecido bisonte, que se vuelve nuevamente pacífico 
y manso en cuanto el cuidador, que comprendió lo que pasaba, se pone la ropa que el animal conoce.

De estas interesantes observaciones, Cuvier no podrá sacar todas las conclusiones. Por un lado, no tiene la teoría adecuada: se trata de fenómenos ligados a la territorialidad y al "imprinting" (marcaje o troquelaje), que son explicados actualmente en términos de "programas" instintivos abiertos, semiabiertos o cerrados, según sea el caso; por ejemplo, el objeto o animal a quien un individuo deberá temer, obedecer y seguir ciegamente, se "imprime" con una imagen: "bisonte", "hombre" u otro ser en movimiento (una cebra seguia siempre a un yip). Pero estuvo cerca de llegar a lo que podríamos llamar una preteoría al respecto: en el caso de los hábitos vio algo que lo podia haber llevado a descifrar ciertas pautas de comportamiento como las mencionadas anteriormente, pautas que, por cierto, harían famosos más tarde a Heinroth y Lorenz (como el caso de los gansos que los seguían, como si ellos fueran sus progenitores).

Pero no lo logró. En efecto, al dicutir contra Dugald-Steward el fenómeno del hábito, nos dice:

Percibimos, no lo que sentimos, sino lo que hemos aprendido a percibir. ${ }^{23}$

Basta que hubiera visto en el instinto una sensibilidad innata, anterior a todo tipo de aprendizaje - que sin embargo despertara en los animales comportamientos parecidos a los que genera el aprendizaje-, para que hubiera revolucionado la etología, sin salirse de su posición fixista. Por otro lado, su explicación, demasiado mecanicista, será insuficiente para dar cuenta del problema de la herencia de los hábitos, tal como parece acontecer entre los animales domésticos.

El estudio de la domesticidad fue en Darwin tan importante como el de la biogeografía. Mucho antes que el naturalista inglés - quien, como se sabe, era un gran conocedor de los animales domésticos, en particular un colombófilo experto-, Cuvier señala que, en realidad, a los animales no se les enseña nada, sólo se les perfecciona en sus comportamientos instintivos: el póinter tiene tendencia a quedarse inmóvil al oler las aves; se le pueden enseñar gracias, como la de levantar la pata o parar la cola, pero eso no se puede hacer con cualquier perro, como tampoco se le podría enseñar al póinter a juntar las ovejas de un rebaño a la manera de los perros pastores.

23 "Examen de quelques observations de Dugald-Steward, qui tendent à détruire l'analogie des phénomènes de l'instinct avec ceux de l'habitude", M.M.H.N., vol. 10, 1823, p. 14. 
Cuvier sabía también que, al combinar razas que manifiestan diferentes comportamientos, se obtienen combinaciones de los mismos: la mezcla de un perro cualquiera con mastín le dará bravura a la descendencia; con algo, tendencia a perseguir liebres, etc. Por lo anterior, la naturaleza del animal permanece constante, se lo esclavice (es el término empleado por Cuvier) o no, aunque es indudable para él que existen pequễus variaciones debidas aî clima, a la alimentación e incluso al hábito prolongado durante generaciones.

Sobre este punto Cuvier se enfrasca en una discusión con un contrincante, que bien puede ser el creador del término "etología": Isidore Geoffroy St.-Hilaire. ${ }^{24}$ Frédéric se defiende de un aparente argumento en contra de su tesis, según el cual:

Sólo los animales libres se muestran a nosotros tal como son, tal como han sido hechos, con el complemento de sus facultades. ${ }^{25}$

Para complementar este argumento, se había dicho, respecto de los animales que vivían en cercanía de las sociedades humanas, como los castores, que habían discontinuado el hábito de su sociabilidad, v. gr., que habían dejado de construir moradas. Para Cuvier, el comportamiento solitario o gregario de cualquier animal, incluyendo el castor, está regido por fuerzas orgánicas más poderosas que las que supone este argumento:

Las condiciones pueden cambiar, la naturaleza de los animales no cambia en nada; si algunos actúan de manera diferente de los otros, producen efectos diferentes; estos efectos son siempre relativos a las facultades del ser que los manifiesta, ${ }^{26}$

es decir, que en toda circunstancia los animales no hacen sino

satisfacer una necesidad ciega, frente a la cual están en cierta forma forzados a obedecer. ${ }^{27}$

Cuvier da un ejemplo que, viniendo de un hombre sin mucha experiencia de campo como él fue, resulta muy interesante: un rumiante, con una naturaleza dada, sería, en un paraje con abundancia de pastos como la Patagonia, un ser pasivo, que se movería poco y que sólo el

24 Cfr., nota 13.

25 "Essai sur la domesticité des mammifères", Annales du Muséum d'histoire naturelle, 1926, pp. 2-3.

26 Ibid., p. 4.

27 Ibid., p. 13. 
fenómeno del celo o de la dominación provocaría en él presión para actuar; ese mismo animal, en tierras con pocos pastos, sería un animal que deambularía incansablemente para sobrevivir. La naturaleza de los animales tiene, pues, un margen grande de flexibilidad. Pero las causas ambientales ocupan una importancia menor frente a las causas internas que mueven al animal y que pueden empujarlo a manifestar pasiones incontrolables, sin que haya ninguna causa externa aparente que las provoque. Huelga decir que circa 1830 estaban muy lejos de saber que existen las hormonas.

Ahora bien, la debilidad del mecanicismo y del fixismo de su teoría, surge cuando Cuvier quiere explicar observaciones que indican la variabilidad de los animales. ¿Cómo cambian los instintos, si descartamos la causa superficial de la cruza? Nos dirá que por el prolongado ejercicio de ciertos hábitos que la naturaleza o el hombre imponen a los animales, lo que es sin duda una tesis transformacionista.

Por lo anterior, está claro por qué Frédéric no puede aceptar sin modificaciones la definición del instinto de su hermano (cfr., p. 9) y debe proponer la suya propia:

El carácter de invariabilidad que se ha dado a las acciones instintivas no debe ser tomado en un sentido completamente absoluto. El animal conserva siempre el ejercicio de sus sentidos, el grado de inteligencia que le es propio y emplea ambos de la manera más favorable en la acción instintiva en la que está siendo llevado. ${ }^{28}$

Estamos, pues, lejos de una visión simplemente mecanicista del animal y cerca de la imagen "poblacional" de Darwin, que parte de la idea de que un conjunto de individuos pertenecientes a una variedad, raza o especie, manifiestan fluctuaciones, a veces importantes, susceptibles de constituirse en el germen de una nueva variedad, raza o especie. En ese sentido, un intento de explicación proveniente de un transformacionista como Geoffroy estaría más alejado de Darwin, por su antropomorfismo, que la de Cuvier. En efecto, para Geoffroy:

Es seguro que, aunque los animales nazcan con un instinto determinado, lo modifican sin embargo cuando cambian de localidad o cuando cambian los seres entre los cuales viven: de esta forma el ave de presa varía sus astucias de acuerdo con los hábitos que son propios a cada especie: da vueltas alrededor de su presa o cae a plomo sobre ella, según sea la especie de que se trata. Por otro lado, la presa combina su defensa con su huida sobre la base de los recursos que sabe que su agresor puede usar. ${ }^{29}$

28 "De l'instinct" en Dictionnaire des Sciences Naturelles, op. cit., vol. 23, p. 534.

29 "Observations sur l'affection mutuelle de quelques animaux, et particulièrement sur les services rendus au Requin par le pilote", M.M.H.N., vol. 15, 1827, p. 439. 
A pesar de su relativa cercanía a las tesis de Darwin, ¿̨por qué Cuvier no sacó de los hechos, que conocía de primera mano, conclusiones que lo llevaran por el camino de la evolución? La primera respuesta, de Perogrullo, es que Cuvier no buscaba lo mismo que Darwin y, en consecuencia, no podía llegar a las mismas respuestas. Aunque, en lo que respecta al problema del instinto trabajó en campos muy cercanos a los del naturalista inglés, y aunque tenía un cúmulo de datos empíricos importantes, no contó con el conjunto fundamental de los datos biogeográficos y se encontró apresado en la teoría fixista.

Existe otra coincidencia, esta vez negativa o por omisión, entre los dos naturalistas. En efecto, ambos carecían de la teoría genética moderna. Hay que recordar que, hasta la demostración de Pasteur, la epigénesis (formación de seres vivos a partir de un germen incompleto -nisus formativus - que se transmite por vía de generación) y la generación espontánea eran aún defendidas por varios naturalistas. Tanto Cuvier como Darwin recurrieron a pseudo-explicaciones para dar cuenta de la transmisión de los caracteres adquiridos, tratando ambos de distanciarse de las tesis lamarckianas.

El origen de nuevos instintos y la necesidad de una disciplina cientifica adecuada

El punto fundamental en el intento cuvierano por explicar cómo los cambios provenientes del clima, del lugar geográfico, de la alimentación y de la acción del hombre, crean hábitos que pasan a ser instintos hereditarios al cabo de varias generaciones, es, en mi opinión, el de parchar la tesis fixista con un remiendo transformacionista. Cuvier se aventura en una explicación, utilizando, ahora, dos tesis que combatió primeramente al defender una posición mecanicista frente al instinto: a) la tesis, vieja como Aristóteles, de que los animales tienen inteligencia, pero en menor grado, y $b$ ) que los hábitos adquiridos de alguna manera se heredan, tesis lamarckiana por excelencia.

En relación a la primera, nos dirá que, aunque la sociabilidad es un instinto común a muchas especies, desde los insectos hasta el hombre, pueden sin embargo existir esfuerzos no instintivos que favorezcan un cambio:

Tendencias particulares, instintos especiales $y$, sobre todo, una gran inteligencia pueden reforzar y perfeccionar el instinto de sociabilidad (...) es sin duda el instinto de la sociabildad, llevado a su más alto grado y unido a veces a una inteligencia notable, lo que debemos a los animales domésticos. ${ }^{30}$

30 "De la sociabilité...", op. cit., pp. 16-17. 
Esta generalización contradice, por cierto, una interesante observación, que bien podía ser de un Darwin, en el sentido de que los animales probablemente más inteligentes, como los simios, son domesticables, pero nunca se vuelven domésticos.

En cuanto a la segunda tesis, Cuvier insistirá en el efecto acumulativo del tiempo:

Es posible sin duda que, a fuerza de buenos tratos, ejercidos con perseverancia sobre varias generaciones sucesivas de animales no sociables, se les llegue a habituar a vivir con nosotros. ${ }^{31}$

Pero sucede que; en seguida, el propio autor plantea dudas fundamentales al respecto: el hábito social está lejos de ser un verdadero instinto social; por otro lado, ¿cómo saber a partir de qué momento un hábito se convierte en instinto? Por ejemplo, ¿en qué momento los hombres comenzaron a domesticar animales? La respuesta a esta interesante pregunta, poco desarrollada, nos da luz sobre un prejuicio, compartido por cierto con Darwin y típico de la época, en relación con el hombre primitivo. Como se trata de seres inferiores, Cuvier duda que se hayan encontrado animales domésticos acompañando a hombres primitivos, lo cual no sólo es falso, sino que destruye el propio intento de explicación por proceso acumulativo que había intentado. En todo caso, si hubiese llevado a fondo este razonamiento, hubiera encontrado que, si los hombres primitivos no podían haber iniciado el proceso de domesticación, entonces un accidente, el azar, y no la inteligencia o el simple hábito, deberían constituir el punto de partida. Pero Cuvier, de nuevo, no podia ver aquí lo que para Darwin fue una evidencia luminosa.

Cuvier se da cuenta de que su explicación del origen del instinto nuevo, a través de un hábito prolongado con la ayuda de la inteligencia, constituye un argumento muy frágil. Pero adopta la posición positivista de considerar que el problema es demasiado novedoso para que la ciencia, en el estado de desarrollo en que se encuentra, pueda solucionarlo. Pero también comprende que es necesario constituir una nueva disciplina para conocer y ordenar el enorme cúmulo de efectos que el estudio de los animales manifiesta al observador:

Se trataría ni más ni menos que de crear la ciencia de una de las ramas más importantes de nuestra industria, la conducta de los animales, es decir, someter a leyes fundadas sobre la naturaleza las prácticas ciegas y las reglas empíricas. 
Se trataría de una disciplina nueva que estudiaría el "origen o las causas eficientes de las acciones de los animales". ${ }^{32}$

Sin embargo, si los efectos se pueden conocer y clasificar, las causas y las leyes, bien por tratarse de instancias primitivas, es decir, que se remontan al origen de las cosas, están, probablemente igual que los designios divinos, fuera del alcance de toda ciencia nueva o vieja:

La causa de ese fenómeno (el instinto) es primitiva; ahora bien, a menos que nos remontemos a la fuente de todos estos tipos de causas, permanecerán para nosotros como potencias escondidas, fuerzas ocultas que nos hacen padecer pasivamente sus leyes; y, desgraciadamente, la mayoría de ellas tienen su fuente mucho más allá de los límites actuales de nuestros conocimientos. ${ }^{38}$

\section{La revolución darwiniana y el concepto de instinto}

Darwin se plantea de manera muy simple que las variaciones morfológicas y conductuales son raras - por lo que la evolución es un fenómeno lento y gradual-, pero cuando aquéllas se dan y son favorables al individuo o a la población que las manifiesta, entonces la selección natural asegura su reproducción y posterior dominio sobre las variedades originales que están en su área geográfica o en áreas geográficas que serán recolonizadas. Darwin no necesita del concepto de inteligencia en los animales, ni de que los hábitos prolongados sean hereditarios, pues incluso en el caso de animales domésticos no se trata más que de selecciones continuas en el tiempo, realizadas por el hombre, aunque la causa de las variaciones siga siendo el azar, intervenga o no el reforzamiento de las cruzadas selectivas y de otros mecanismos secundarios.

El naturalista inglés no contó con la experiencia cuvierana de observación y experimentación con animales cautivos, pero tuvo la extraordinaria oportunidad de conocer y verificar de cerca el fenómeno de variación y de dispersión de una especie en especies y variedades distintas, distribuidas según la influencia directa de accidentes geográficos (erupciones volcánicas, vientos y corrientes marinas dominantes, etc.), como en el caso de las Islas Galápagos. En esas islas también pudo asistir, asombrado, al espectáculo que le ofrecían animales que no manifestaban el más mínimo temor al hombre, a pesar de haberlo padecido por lo menos desde hacía tres siglos: un niño degüella, ante los ojos del inglés, a pájaros que van a beber a una fuente y que siguen yendo a su muerte, a pesar de "ver" lo que les está pasando a sus congéneres; 
una iguana marina molestada por él, cuando es tirada al agua, regresa a tierra, como buscando instintivamente refugio en tierra firme, donde permanece, sin embargo, el naturalista agresor. Esto le hace concluir que la selección natural actuó con un solo depredador del reptil, a saber, el tiburón.

En el capítulo "Instinct" del Origen de las especies, Darwin da explicaciones claras y elegantes a problemas que Cuvier destacó pero que, como vimos, no pudo explicar dentro de su teoría. En primer lugar, Darwin nos dice que "Natura non facit saltum". ${ }^{34}$ Las modificaciones aparecen por pequeños cambios, lo que nos permitiría, en teoría, poder remontarnos en la evolución de una especie, hasta sus ancestros más lejanos - si contáramos con el conocimiento de todas las variaciones que existieron- o, de la misma manera, demostrar su parentesco con otras. Así, por ejemplo, Darwin analiza la evolución en la construcción de los panales de abeja, partiendo del estudio de las obras de las avispas, para llegar a la conclusión de que la selección natural favorecerá siempre aquellas estructuras que mejor contribuyan a la propagación de la especie en el área geográfica (en el nicho ecológico, diríamos hoy) en que se encuentra:

As natural selection acts only by the accumulation of slight modifications of structure or instinct, each profitable to the individual under its conditions of life, it may reasonably be asked, how a long and graduated succession of modified architectural instincts, all tending towards the present perfect plan of construction, could have profited the progenitors of the hive-bee? I think the answer is not difficult: cells constructed like those of the bee or the wasp gain in strength, and save much in labour and space, and in the materials of which they are constructed. ${ }^{35}$

En su análisis Darwin hace referencia a la relación de los hábitos con los instintos, que discutió Cuvier, y no descarta la posibilidad de que hábitos adquiridos tiempo atrás hayan sido hereditarios - cosa que no aceptarían los neo-darwinianos-, pero tiene el acierto de atenerse al estudio de los instintos menos ligados al hábito, como son los de los insectos y las aves:

It can be clearly shown that the most wonderful instincts with which we are acquainted, namely, those of the hive-bee and of many ants, could not possibly have been acquired by habit. ${ }^{36}$

34 The Origin..., op. cit., p. 134.

3.5 Ibid., p. 130.

36 Ibid., p. 119. 
De paso, Darwin anuncia los trabajos de tipo estructuralista que más tarde desarrollará Köhler, al mostrar que los procesos del hábito y del instinto deben seguir un "ritmo", una estructura temporal: un pianista que se para en un punto de la partitura que toca de memoria, deberá volver a comenzar, si no desde el principio, por lo menos desde la "sección" anterior, en lo que se parece a la oruga de la que hablamos antes. ${ }^{37}$

En el estudio de los instintos, se aplica sin restricción la tesis darwiniana de la selección natural, dejando aparentemente de lado todo fenómeno de tipo aprendido:

Under changed conditions of life, it is at least possible that slight modifications of instinct might be profitable to a species; and if it can be shown that instincts do vary ever so little, the I can see no difficulty in natural selection preserving and continually accumulating variations of instinct to any extent that was profitable. It is thus, as I believe, that all the most complex and wonderful instincts have originated..$^{38}$

Lo que hace la selección natural lo puede reforzar el ganadero o cualquier criador de animales, al favorecer la reproducción de aquellos animales cuyas características desea ver multiplicarse, aun sabiendo que la descendencia de los mismos será mixta: algunos tendrán las características deseadas y otros no. El proceso debcrá ser reiniciado constantemente.

No entraremos aquí en el análisis detallado de los ejemplos que nos proporciona Darwin: la evolución del instinto del cuclillo, cuyas especies europeas y australianas son parasitarias y ponen huevos en nidos de otros pájaros, mientras que la especie americana no lo es; las hormigas que aprovechan las secreciones azucaradas de los pulgones y que tienen "esclavas", y la construcción de celdas por las abejas. Lo interesante de estos análisis, así como el del fenómeno de la domesticación, consiste en que, sin tener una teoría genética consistente, Darwin logra sostener lo fundamental de su paradigma.

Conocemos los intentos fracasados de Darwin por buscar respuestas a los fenómenos de la generación: por ejemplo, pensar que en la selección a través del sexo, si un progenitor tiene un carácter favorecido por la selección, lo transmite aportando el $50 \%$ de la herencia de los hijos, mezclándose con el otro porcentaje de su cónyuge como si fueran dos líquidos. Un matemático inglés contemporáneo de él, Fleming Jenkin, demostró fácilmente que, si ése fuera el caso, el carácter que supuesta-

37 Ver supra, p. 18.

38 The Origin... op. cit., p. 119. 
mente se transmite tendería a disminuir en importancia en generaciones posteriores, tendiendo del $50 \%$ al $0 \%$. Esto hizo a Darwin abandonar esta idea particular y favorecer simplemente la intuición de que las variaciones individuales son las que realmente cuentan. Intentó construir una teoria, la pangénesis, que consistía en un método mecánico de explicar la herencia. Pierre Thuillier lo sintetiza de la siguiente manera:

Suponía que las células de todas las partes del cuerpo emitían "pequeños granos o átomos", denominados gémulas, que circulaban en el organismo y que se agregaban en "elementos sexuales". ${ }^{39}$

Como dice el mismo autor, esta teoría explicaba demasiado _implicaba la herencia de caracteres adquiridos, que Darwin rechazaba- y explicaba demasiado poco, pues no daba cuenta de los atavismos - caracteres que se expresan sólo después de varias generaciones - ni de ningún otro de los fenómenos de la herencia que se han analizado y explicado hasta ahora.

En lo que toca a la genética, Darwin se encontraba en una posición casi tan débil como Cuvier y, sin embargo, su teoría es explicativa. Para mí, el éxito del padre de la teoría de la evolución consiste en no haberse aventurado demasiado en terrenos sobre los cuales no tenía evidencias empíricas realmente paradigmáticas, o en haberlas abandonado al descubrir que no iba a poder sostenerlas. Pero nunca cambió lo fundamental de su teoría paradigmática - la evolución a través de la selección natural—, que siempre defendió con gran testarudez. Es cierto que se podria analizar un sinnúmero de factores adicionales que contribuyeron a que la suya fuera una auténtica revolución científica; mi interés es mostrar la importancia de dos elementos (la teoría paradigmática y los datos empíricos que la sostenian firmemente), que nos permiten apreciar la importancia paradójica que las investigaciones fixistas tuvieron en su obra; pero no me gustaría quedarme sin que otros dos elementos fundamentales que contribuyeron a la revolución darwiniana, la imaginación y la testarudez del naturalista, no pueden, en mi opinión, ser explicados externamente, ni siquiera recurriendo a la misma teoría de la evolución.

39 Thuillier, Pierre, "Darwin état-il darwinien". en La Recherche, op. cit., p. 16. 